REGARDS

SUR L'ECONOMIE ALLEMAND

BULLETIN ECONOMIQUE DU CIRAC
Regards sur l'économie allemande

Bulletin économique du CIRAC

$74 \mid 2005$

Varia

\title{
Un pari courageux et raisonnablement risqué
}

\section{René Lasserre}

\section{OpenEdition}

Journals

Édition électronique

URL : http://journals.openedition.org/rea/68

DOI : $10.4000 /$ rea. 68

ISBN : 978-2-8218-0844-7

ISSN : 1965-0787

Éditeur

CIRAC

Édition imprimée

Date de publication : 1 décembre 2005

ISSN : 1156-8992

\section{Référence électronique}

René Lasserre, « Un pari courageux et raisonnablement risqué », Regards sur l'économie allemande [En ligne], 74 | décembre 2005, mis en ligne le 22 avril 2008, consulté le 21 septembre 2020. URL : http:// journals.openedition.org/rea/68 ; DOI : https://doi.org/10.4000/rea.68 


\section{Un pari courageux et raisonnablement risqué}

Après de nombreux rebondissements et de longues discussions entre les états-majors, le contrat de coalition a été adopté par les deux grands partis et le nouveau gouvernement d'Angela Merkel est maintenant aux commandes. Comme il est de règle en Allemagne, la formation de ce gouvernement et l'élaboration de son programme ont été largement relayés dans le débat public. Les choix ont été clairement affichés, passés au crible des experts et vivement controversés, pour ne pas dire fraîchement accueillis. La chancelière et son équipe gouvernementale ont su faire front en défendant solidairement et courageusement leurs options, de sorte que ce programme gouvernemental, expression de la volonté commune des deux grands partis, est désormais pleinement assumé devant l'opinion. Bel exemple de démocratie.

Ce programme n'emporte certes pas d'emblée la conviction, car il repousse à une seconde phase des arbitrages difficiles mais essentiels, en particulier la refonte du système fiscal ou celle du mode de financement des régimes de protection sociale. Mais, dans l'immédiat, à défaut de pouvoir s'engager sur tous les fronts, le gouvernement s'attaque en priorité au problème crucial de la consolidation budgétaire et de la réduction de l'endettement. Il s'agit d'un choix courageux et lucide car rien ne pourra être entrepris de durable aussi longtemps que la dérive financière ne sera pas maitrisée. Tant qu'elle sera hypothéquée par les déficits et le poids de la dette, la reprise ne parviendra pas à créer suffisamment de richesse et d'emplois et à enclencher une dynamique de croissance durable. Et tant que les marges de manœuvre financières n'auront pas été en partie restaurées, les pouvoirs publics reculeront devant les réformes de structure nécessaires pour assurer la compétitivité et l'avenir du pays.

Reste que s'il est courageux, le pari est risqué car la voie choisie est étroite et périlleuse. A défaut de pouvoir s'engager dans une politique de réduction brutale des budgets publics et des dépenses sociales, le gouvernement opte pour un plafonnement rigoureux des dépenses qu'il lui faut obligatoirement relayer par un renforcement substantiel de la pression fiscale. A lui seul, le gel des dépenses ne saurait en effet suffire à financer les 70 milliards $€$ nécessaires pour ramener le déficit en dessous des $3 \%$ à l'horizon 2007, pas plus d'ailleurs que la suppression programmée des exonérations et privilèges fiscaux de tous ordres qui ne produira ses effets que dans la durée. Pour l'essentiel, c'est bel et bien sur la hausse des impôts et en premier lieu sur celle de l'impôt sur la consommation que repose la politique d'assainissement budgétaire et financier. Même s'il n'est programmé qu'au $1^{\text {er }}$ janvier 2007, dans un contexte conjoncturel que l'on espère sensiblement amélioré, le relèvement de 3 points de la TVA n'en présente pas moins le risque économique majeur de peser lourdement sur la demande intérieure et de venir étouffer la croissance à peine retrouvée.

On objectera que la hausse de la TVA servira également à financer la baisse des cotisations chômage de 2 points, ce qui est loin d'être négligeable, mais reste très modeste au regard du poids trop élevé des charges salariales et de la hausse programmée des cotisations retraite. Plus positif est le fait que parallèlement à la réduction des déficits, la 
hausse des recettes fiscales permettra également de soutenir la croissance à travers un ensemble de mesures ciblées en faveur de l'investissement et de l'innovation. Ce "policy mix" devrait permettre de conjurer au moins en partie le scénario catastrophe d'une hausse des impôts sans croissance.

Pour être prudent, le pronostic n'en doit pas moins rester optimiste : les signes de la reprise en Allemagne sont désormais tangibles et incontestables ; les entreprises allemandes disposent, en dépit de leur charges, d'une compétitivité internationale solide qui leur assure des performances record sur le marché mondial ; l'économie allemande, pourtant très dépendante des approvisionnements et des marchés extérieurs, a remarquablement bien tenu le choc de la hausse des prix de l'énergie et du cours élevé de l'euro. De plus, le site Allemagne dispose, plus que jamais, de solides atouts en termes d'excellence et de compétitivité territoriales, comme le montrent les deux enquêtes que nous publions dans ce numéro sur le Land du Bade-Wurtemberg et sur l'innovation dans les PME.

Si dans ce contexte à nouveau porteur, et conformément aux attentes, la reprise parvient effectivement à se consolider dans les prochains mois, l'économie allemande devrait pouvoir absorber sans trop de dommages la hausse de la TVA. La politique de redressement budgétaire pourrait alors porter le premier et le principal de ses fruits : redonner aux acteurs la perspective d'un cadre de politique économique assaini, dans lequel il sera possible de construire de nouveaux équilibres. L'heure sera alors venue pour Angela Merkel et son gouvernement de poursuivre le travail entrepris et d'engager résolument les réformes tant attendues.

René Lasserre

(06-12-05) 